Max-Planck-Institut für demografische Forschung

Max Planck Institute for Demographic Research

Konrad-Zuse-Strasse 1 - D-18057 Rostock · GERMANY

Tel +49 (0) 3812081 - 0; Fax +49 (0) 3812081 - 202;

http://www.demogr.mpg.de

MPIDR WORKING PAPER WP 2005-007

MARCH 2005

\title{
The cost of population aging: \\ forecasting future hospital expenses in Germany
}

Hilke Brockmann (brockmann@gsss.uni-bremen.de)

Jutta Gampe (gampe@demogr.mpg.de)

This working paper has been approved for release by: James W. Vaupel (jwv@ demogr.mpg.de)

Head of the Laboratory of Survival and Longevity.

(C) Copyright is held by the authors.

Working papers of the Max Planck Institute for Demographic Research receive only limited review. Views or opinions expressed in working papers are attributable to the authors and do not necessarily reflect those of the Institute. 


\section{Abstract}

Forecasts are always wrong. Still, they paint potential future scenarios and provide a platform for policy decisions today. This is what gives forecast such a high salience in political debates about the effects of population aging. The paper aims at gauging the effect of population aging on hospital expenses in Germany. We use a probabilistic forecast model comprising a stochastic demographic component that exploits historical mortality trends, a stochastic cost component based on typical hospital costs over the lifecourse, and a quality measure of medical progress, which builds on past advances in hospital treatment. Three different scenarios are constructing, yielding 3 important results. Firstly, there is an increase in overall hospital expenditure until the German baby boomers will die out (2040 to 2050). Secondly, the increase is comparably moderate because the average individual costs are likely to decline as elderly health improves and since medical progress has an ambiguous influence on hospital expenditures. Finally, the cost increase varies significantly by gender and disease. 


\title{
The Cost of Population Aging
}

\section{Forecasting Future Hospital Expenses in Germany}

\author{
Hilke Brockmann \& Jutta Gampe
}

\section{INTRODUCTION}

Population aging is not a new phenomenon. Since the early $19^{\text {th }}$ century, life expectancy in the modern world has been increasing at all ages, and primarily among the oldest-old since 1950 (cf. Vaupel et al., 1998; Gjonça, Brockmann \& Maier, 2000; Oeppen \& Vaupel, 2002). What is new, however, is that population aging has become a political hot topic owing to the chronic fiscal problems of the welfare state, the latter which throughout the OECD has been "first of all a welfare state for the elderly" (Guillemard, 1983, p.3). Given that the baby boomers are working in times of fiscal stress today, how will the welfare state be affected once they retire?

Most forecasts predict an impending cost explosion in public pensions and health care. Some economists and politicians thus have suggested to introduce set age limits to apply to insured health provision in the Germany of the future. Public health insurance funds should, for example, stop payment for costly and life-sustaining health treatment for people aged 75 and over (Breyer \& Schultheiss, 2003a, b; Report Mainz, 2003). Before implementing such draconian measures, however, we should be certain that health care costs will indeed explode as predicted. In this paper, we contend that they may no do so: We have reason to believe that the effect of population aging on health care costs will be cushioned more so than is commonly assumed. 
In order to gauge the effect of population aging on health care expenditure, we have to look at how aging interacts with the two main legitimate drivers of health care costs: health care utilization and medical progress (Getzen, 1992; Cutler \& Sheiner, 1998; Breyer \& Ulrich, 2000a, b; Blumenthal, 2001; Freund \& Smeeding, 2002).

Does population aging drive up the rate of health care use? Or, how healthy will the elderly be in future? Most forecast scenarios based on deterministic assumptions seriously underestimate elderly life expectancy and health in advanced western societies (Robine, Mormiche \& Sermet, 1998; Tuljapurkar, Li \& Boe, 2000; Doblhammer \& Kytir, 2001; Oeppen \& Vaupel, 2002). We, by contrast, base our probabilistic forecasts on empirical data of past mortality development and individual data on hospital use to project future health care needs, thus hoping to arrive at a more accurate prognosis of elderly life expectancy and health.

Does medical progress magnify or mollify the financial burden of future health care? Are older patients disproportionately benefiting from medical progress? Although it is now a standard assumption that technological expenses grow at a higher rate than GDP (Lee \& Miller, 2001a; Technical Review Panel, 2000) recent studies on single medical technologies have cast doubts as to its validity. They demonstrate that medical progress can, in fact, reduce treatment costs on the unit level (Cutler \& McClellan, 2001) as well as on the overall level when quality is accounted for (Cutler, McClellan, Newhouse \& Remmler, 1998). We address these findings by including a quality measure of medical outcomes in our projections. In doing so, we focus on hospital costs and do this for two reasons: a) hospitals make use of the most progressive medical technology, b) hospital expenditure ranks on top in health care spending. Finally, patients have little interest in 
overusing hospital services; the moral hazard risk of hospital treatment therefore is comparatively low.

Our forecast yields three important results. First, overall hospital care expenditure in Germany will rise between 2040 and 2050. Second, the increase is a relatively moderate one, average individual costs are likely to decline because elderly health will improve, and medical progress has an ambiguous impact on hospital expenditure. Finally, the cost increase will vary significantly by gender and disease.

The remainder of the paper is organized as following. At first, we first provide general background information on health care forecasts. We then discuss the empirical methodology of this study, present our results and conclude.

THE BACKGROUND ON HEALTH CARE FORECASTS, OR, HOW TO LINK DEMOGRAPHY WITH MEDICAL PROGRESS

\section{Forecasts using Cross-Sectional Data}

Since public health care is mostly financed on a pay-as-you-go basis, many studies and official forecasts extrapolate from aggregated annual expenses to future health care costs (Espenshade \& Braun, 1983; Prognos, 1998, Mayhew, 2000, 2001; Board of Trustees, 2000). This cross-sectional approach is straightforward and gives priority to demography. Age-specific annual expenditures are weighted by the proportion of the given age group in the population total. Population aging is introduced by changing the age weights in line with demographic forecasts. Medical technology and factor costs implicitly or explicitly grow at the same rate as the economy does. As a consequence, health care budgets must 
rise as the number of elderly people increases (Waldo, Sonnefeld, Lemieuy \& McKusick, 1991; Warshawsky, 1994). Knappe (1995), for example, calculated that the contribution rates to German health insurance have to rise from about $13.5 \%$ on average in 2000 to $25 \%$ of earnings by 2030 to cushion the financial effect of aging.

\section{Forecasts with Time-Series Data}

Getzen (1992, p.99) has criticized age-group projections for offering mere "what if"predictions of hypothetical demographic effects while ignoring the empirical dynamics of population aging and medical progress over time. In order to reflect longitudinal trends, he regressed the health care spending of 20 OECD countries for the years 1960 to 1988 on the percentage of people aged over 65 on growth rates in GDP and on a trend variable. The author found that population aging is associated with health care spending only when all other variables are left aside. Including per capita income and a time trend absorbs the age effect completely. In fact, countries with a relatively high percentage of elderly (like Denmark and Norway) are neither more nor less likely to have higher health care expenses.

Country specific studies, by contrast, often find a significant but minor effect of population aging on health expenditure. Newhouse (1992) has estimated that the growing technical sophistication of medicine accounts for more than $50 \%$ of rising medical costs in the United States. The impact of the country's elderly population, of rising income, and health coverage that is increasingly generous is much weaker.

Breyer and Ulrich (2000a) have regressed the growth in expenditure specifically of Germany's compulsory sickness funds of 1970 to 1995 on the real income of insured members as a proxy for productivity and process innovation, on calendar years as an 
indicator for medical progress, and on the proportion of insured members aged 65 and over. Their regression equation explains to more than $98 \%$ the resulting variance and shows that technological progress increases health expenditures by $1 \%$ annually. An expansion in the elderly population by $1 \%$ raises per capita expenses significantly, by $8 \%$. Fitting these regression results into an official population projection scenario leads to an increase in health insurance contributions from about $13 \%$ to $16 \%$ in 2000 to $23.1 \%$ in 2040.

\section{Forecasts using Life-Cycle Data}

However, recent individual and cohort level studies raise doubts as to the predictive value of purely demographic scenarios and aggregate economic trends. Tracing individuals over their life-cycle shows that proximity to death rather than chronological age determines the left-skewed distribution of health care costs over the lifetime (Turnbull et al., 1979; Schroeder, Showstack \& Schwartz, 1981; Scitovsky 1984, 1988; Zweifel, Felder \& Meier, 1999; Yang, Norton \& Stearns, 2003). The schedule of health care expenditures seems to be stable over time (Lubitz \& Riley, 1993; Garber, MaCurdy \& McClellan, 1998). What is more, health care expenditures over the last years of an individual's life increase less so among older people and the oldest-old than among younger people at the last stages of their life (Lubitz, Beebe \& Baker, 1995; Brockmann 2002; Felder, Meier \& Schmitt, 2000). This suggests that an aging population may cause a rise in health care expenditure that is less pronounced than commonly assumed.

Miller and Lee (Miller, 2001; Lee \& Miller, 2001) have translated life-course expenses into national forecasts of Medicare expenditures. In contrast to age group projections, they have used average Medicare costs by time-to-death and have weighted these expenses 
with the percent distribution of time-to-death years in future populations. The mean and the entire distribution of time-to-death for individuals of a certain age have been obtained from cohort life tables. Official forecasts and time series have been used to project future US mortality rates. As to his results, the time-to-death approach did forecast lower Medicare expenditures than did a simple age-group projection. Official forecasts may systematically under-project mortality declines and gains in life expectancy. Miller has made out a difference in Medicare expenses of 14\% in 2070 between the two approaches (Miller, 2001). In addition, simulating probabilistic mortality forecasts based on historical data reveals diverging expenditure patterns after 2015, when the American baby boomers will enter Medicare. Before that date, longevity does not incur rising health care costs. Long-term projections show, however, that increasing longevity will trigger a transition from short-term decline in Medicare expenditures to an increase later on due to the growth in the number of elderly.

\section{Technological Life-Cycles}

Miller's paper (2001) has a major shortcoming, though, in that he has neglected technological change. Even though empirical proof is rare and national variation is high, technological change is generally held to be a major cost driver in health care (Cutler, 2003; Blumenthal, 2001; Mohr, 2001; Okunade \& Murthy, 2002; Zweifel \& Manning, 2000). In a another paper, Lee and Miller have added to their projection the mean growth rate from the Medicare Trustees Technical Report but acknowledge having thereby „outsourced the single most important component of our forecast" (Lee \& Miller, 2001, p.7). This is very unfortunate since the life-cycle approach turns out to be a useful tool to understand the link between medical progress and health care costs. 
Thomas (1975) and Weisbrod (1991) have traced the cost profile of medical technology over technology's life-cycle. At an early stage in the life-cycle, when not much is known about a given disease, the therapy is a palliative and inexpensive one. Suffice it to mention ALS (Amyotrophic Lateral Sclerosis) as an example. The second stage is achieved when "halfway technologies" successfully treat the symptoms at hand. An example would be cancer treatment aimed at fighting established cancer cells but not combatting the actual cause „by which cells become neoplastic“ (Thomas, 1975, p.39; Weisbrod, 1991, p.533). These therapies are very cost-intensive; because they keep the disease chronic. At the last stage of the life-cycle, therapies are based on a genuine understanding of the mechanisms behind a given disease and cure patients at low cost. Many infectious diseases are at this stage, and vaccination may even stamp out the illness.

Picking up on the life-cycle idea, Pardes et al. $(1999$, p.36) have investigated the extent to which an understanding of human biology at the molecular level and resulting preventive and tailor-made gene therapies or less expensive genetically engineered pharmaceuticals replace costly invasive surgery, intensive care-units, or long-term nursing home care. Cutler and Huckman (2003) have provided further empirical evidence by studying the development and productivity of treatment for coronary heart disease. In an earlier study, Cutler et al. (1998) have shown that the financial costs of heart attack treatment has fallen by about $1 \%$ annually in tandem with improvements in the quality of treatment.

In sum, life-cycle studies suggest that technological change and population aging do not necessarily increase health care expenditure. In predicting future health care costs, it is imperative, therefore, to account for the dynamics of technological development and individual health trajectories. 


\section{DATA AND METHODS}

\section{Data}

Our forecast model draws on three different data sources. First, we use the Human Mortality Database (HMD) for the years 1956 to 1999 to forecast future mortality and future population size. The HMD provides population data for both sexes, for single-year age groups, and single period years. Ages 95 and over have been collapsed to attenuate large fluctuations due to small sample sizes.

The second source consists of individual level hospital expenditures; these are based on hospital claim files from Germany's largest public health insurer, Westphalia-Lippe (West Germany). We use data from their regional fund, which at the time of analysis registered 480,329 members aged 65 and over. Westphalia-Lippe provides a representative sample of Germany, with 65 years being the compulsory retirement age. Individual healthcare costs have been summed up when they occurred during the previous 365 days before the date of last discharge in 1997. If a hospital stay extended beyond this period, then we have accounted only for those days that fell within the defined individual year and have calculated the mean daily costs.

Finally, we have used official aggregate hospital data from 1993 to 1999 (Statistisches Bundesamt, 2003b).

\section{Models and Measures}

We model the main determinants of future health-care expenses seperately - the number of elderly, their health status, and progress in medical treatment - in order to study their individual impact on aggregate outcomes. Predictions are inherently uncertain, and 
we take this into account. Our model comprises a stochastic demographic component that exploits historical mortality trends, a stochastic cost component based on typical hospital costs over the life-course, and a quality measure of medical progress, which builds on past advances in hospital treatment. Different scenarios will be simulated (cf. Appendix).

Demographic Forecasts.- Official population forecasts have been criticized by a growing group of demographers, who expect that future populations live longer and have proposed a stochastic model to predict this development (Vaupel \& Oeppen, 2002; Lee \& Miller, 2001; Tuljapurkar, Li \& Boe, 2000; Keilman, 1998). The model adds on historical trends. Lee and Carter (1992) have introduced a model for mortality forecasts that has since then has been applied to data on several developed countries (Tuljapurkar, Li \& Boe, 2000; Booth, Smith \& Maindonald, 2002). Recently, Lee and Miller (2001) have reevaluated the performance of the Lee-Carter model, providing a thorough discussion of its merits and shortcomings (see also Lee, 2000). The Lee-Carter model extracts the first principal component from a series of log death-rates (Lee \& Carter, 1992; Bell, 1997). The resulting time-series of this component are then fitted and predicted using standard ARIMA techniques (Brockwell \& Davis, 1991). The approach has proven to be applicable to German mortality data.

We use West German mortality forecasts based on the period 1970 to 1999 to predict the number of males and females by single year of age from 65 to 94 , and an aggregate age group for age 95 and over. The prediction period is 65 years. Furthermore, the number of people surviving one year of age and those dying during that year are determined. This distinction is necessary to assign hospital costs appropriately (see next section). 
Individual Hospital Costs.- Individual costs (on a log-scale) were estimated to be of a linear function as to the length of stay (also on the log-scale), a quadratic function of age, and an ICD-specific intercept. Separate models were estimated for surviving and deceased men and women. Regression diagnostics suggest excluding patients who incurred expenses of less than $500 \mathrm{DM}(2.9 \%)$. The majority of these cases do not represent true hospital cases, but have arisen from false admissions, misreporting, incorrect billing, or data missing. Since it is not in the interest of hospitals to under-report and over-reporting is not in the interest of the insurer, the remaining data are fairly reliable. Group-specific incidences were estimated from the total number of insured persons by age, sex, and survival status.

The Quality of Technological Progress.- Although medical progress is identified as a major cost-driver, its measurement is far from being standardized. Aggregate growth rates of health care expenditures are often used, but the level of growth varies considerably. Moreover, aggregate measures are affected by perverse effects, such as the moral hazard or supplier-induced demand, and do not reflect quality change in medical progress. We therefore apply indicators of medical advancement that focus on the patient's utility. Medical progress has two preferred outcomes. Firstly, it should make treatments more efficient and compress the time of morbidity. Secondly, it should expand the range of possible treatments so that a fewer number of people will suffer in future from today's diseases. The two outcomes are reflected in two measures: the length of stay in hospital and the range of medical therapies. Although we cannot guarantee that these measures are not affected by perverse effects, we are sure that the probability and the length of stay in hospital is less distorted than are any aggregate measures, like hospital expenditure growth 
rates; this because the manipulation of time spent in hospital is a direct infringement of a patient's rights and interests.

We use of official statistics that cover the decline of the length of stay in hospital over time. During the early 1960s, patients spent more than 28 days on average in hospital or in a rehabilitation clinic. Since 1991, hospital stays have been recorded separately, with the result that patients from then onwards have been spending on average 14.3 days in a West German hospital. Ten years later, the mean duration spent in hospital was 9.8 days (Statistisches Bundesamt, 2003a). Since 1993, the length of stay in hospital has been further broken down by age group and ICD class (Statistisches Bundesamt, 2003b). In order to exploit this detailed information, we calculate the mean decline of the length of stay per year, the age group and the ICD class, and weigh down by this factor simulated future hospital stays. Since individual level data show a significant and systematic decline in time spent in hospital by age, we add an age-adjusted duration to the analysis.

Medical progress improves the possibility to treat an increasing number of diseases. The expansion of medical intervention results in rising numbers of total days spent in hospital per 10,000 inhabitants. Official statistics show that these figures are climbing, although at different rates in different age and disease groups (Statistisches Bundesamt, 2003b). We derive mean growth rates that are age and disease specific and weigh up simulated future utilization rates.

Scenarios.- We draw 3 scenarios. The first focuses on the effect of population aging, holdings all other influences constant. In the second scenario, the subjects of our study enjoy a longer and healthier life. That is, we assume that the higher life-expectancy is accompanied by a slow but steady shift in the proportions of age-specific diseases towards 
higher ages. The third scenario introduces medical progress by shortening the length of stay in hospital according to yearly decline rates of attendance and by taking into account an increasing number of future cases for hospital. Individual-level data shows that younger patients stay significantly longer in hospital than the oldest old (Brockmann 2002). We therefore also consider an age-adjusted length of stay. All scenarios will be broken down by sex and major ICD class (ICD2 representing cancer, ICD7 denoting diseases of the circulatory system, ICD8 diseases of the respiratory system, and ICD17 being accidents, injuries, and poisoning).

\section{FORECASTING FUTURE HOSPITAL COSTS}

Scenario One: Population Aging, or, What will the growing Number of Older Men and Women cost?

Population aging means first of all that the number of older people will increase. When projecting this trend only, we observe a steady increase in overall hospital expenditure from about 24.7 billion Euros to more than 46 billion constant Euros in 2041. When the German baby-boomers born in the 1960s die out, hospital expenses will drop again. In 2065 , hospital costs will amount to nearly 39 billion Euros, that is $157 \%$ of the expenditure for 2000 .

Our forecast reveals stark gender differences. During the entire projection period, the total hospital treatment for women will cost more than that for men. In 2000, hospital expenses for older women were 7.8 billion Euros higher than that for older men and summed 28.1 billion Euros. The gender gap is expected to shrink to 800 million Euros in 
2038 and will remain below $50 \%$ of the current amount, although the difference will increase later.

In terms of relative costs, however, the gender gap is widening as hospital expenses for men will increase at a higher rate than those for women. In 2040, outlays for men will be nearly 2.2 times higher than in 2000. For women, hospital costs will reach a peak in 2043, at 1.6 times the expenses of 2000 , followed by a decline in both expenditure curves though less steeply so than in the increase. The gender gap will remain. The unequal morbidity and mortality regimes of men and women translate into different hospital expenditure profiles at old age.

Figures $1 \mathrm{a}$ and $1 \mathrm{~b}$ about here

Different diseases vary in their contributions to the overall trend. ICD 7, the major killer, is the most expensive disease class. In 2000, hospital treatment added up to more than 3.6 billion Euros for older women who suffered from diseases of the circulatory system, and to more than 3.2 billion Euros for older men. In the following years, however, ICD7 treatment for men will become more expensive than that for women, to reach a peak in 2039 of 7.1 billion Euros. Hospital expenses for women will be highest in 2042, with 5.9 billion Euros. In comparison, the relative increase of hospital expenditure for the treatment of cancer, the second most frequent cause of death, will be lower. The figure will be higher for the treatment of accidents, injuries, and poisoning and will even have gone up to $240 \%$ for men in 2047 and 199\% for women by 2051 .

Average expenditure per insured individual reveals a different outlook. Average hospital costs for a cancer patient will decline steadily during the period of observation. In 
2064, expenses are predicted to be $23 \%$ and $16 \%$ lower for women and men respectively than in 2000. In comparison, we project no time trend for the average expenses incurred by diseases of the circulatory and respiratory system. These outlays will be around the expense level of 2000. Expenses vary between $+/-3.8 \%$ (ICD 7) or $+8.6 \%$ and $-5.3 \%$ (ICD 8 ) for women and $+1.1 \%$ and $-2.5 \%$ (ICD 7 ) or $+7.9 \%$ and $-3.6 \%$ (ICD 8 ) for men. However, hospital expenditures for treating accidents and injuries will increase and peak at $130 \%$ of the equivalent expenditure for women in 2000 and at $122 \%$ for that of men in 2057.

Figure 2 about here

Generally, average expenses per beneficiary neither replicate the route of the total expenditure curves nor reveal any continuous and substantial increases in future hospital outlays. On the contrary, average expenses vary only moderately. The first scenario, is still unrealistic, however, as we assume that the elderly of the future will be as healthy as today's 65 year old and older. This assumption will be relaxed in the next scenario.

Scenario Two: Population Aging of Healthy Elderly, or, How much to pay for Health Improvements?

In general, agreement among demographers abounds that people will live longer because they are healthier. One qualification needs to be made, though: Disagreement, and this is the only one, arises over the extent to which their health will improve. Oeppen and Vaupel (2002) have shown that female life expectancy in record-holding country has been rising in the last 160 years at a steady pace of almost 3 month per year. To be on the safe 
side, we rejuvenate age and ICD-specific incidence rates by 0.1 year annually, meaning that in 10 years time a 66-year-old will have the same health status as a 65 -year-old today.

Figures $3 \mathrm{a}$ and $3 \mathrm{~b}$ about here

Given these health improvements, we observe hospital expenses that are lower than those of the first scenario throughout the whole projection period. Around 2042 and 2065, expenses for men will be reduced by up to 2.2 billion Euros or $21 \%$. For women, the difference sums up to 2.5 billion Euros or $17 \%$ for the same years. In absolute numbers, the gender gap will shrink and disappear for a few years around 2035. In relative numbers, the gender gap will initially grow and stay large after 2035. Until 2040, men's hospital expenditures climb steeper whereas women's hospital expenses will be less health sensitive.

Figure 4 about here

An elderly population that is healthier will also place less financial demands on hospital treatment for the major killers at old age. Per capita expenses for cancer, diseases of the circulatory or respiratory system as well as for accidents, poisonings, and injuries will drop substantially (up to $20 \%$ ) to below their 2000 level. Compared to the first scenario, hospital expenses for women with ICD17 will experience a steep decline by $38 \%$. Money spent on cancer treatment for women, which will also decline over time, is the only expense that is higher, though slightly, in the second scenario compared to the first one. 
Scenario Three: Population Aging, Health Improvement, and Medical Progress, or, How much does Medical Progress add to the Bill?

The demand for hospital care is contingent upon supply. Medical progress will have a decisive influence on the development of health care demand and health care expenditure. The ICD- and age-specific decline in the length of stay in hospital during the last years is our first indicator of medical progress. Figure 5 illustrates the outcome for the two major killers. Hospital expenses would drop by up to $90 \%$, given this development. This is not a realistic scenario, however. The examples nevertheless illustrate the saving potential of medical progress, provided that it would exclusively focus on increasing the efficiency of today's treatment in hospital.

Figure 5 about here

Improving the efficiency of current therapies is an aim of medical progress. Another is the search for effective new treatments. We measure this advancement by the increasing number of hospital treatments per inhabitants over time. Projecting these ICD- and agespecific rates into the future in addition to our previous assumptions reveals that hospital expenditure will increase. Compared to the first and second scenario, however, the expenses will be lower during the first decades, precisely until 2034 rsp. 2039 for women and 2049 rsp. 2013 for men in the first two settings. In later years, medical progress will lead to higher expenses. This applies particularly to men, whose hospital expenses will rise more steeply than those for women, so that from 2022 onwards their hospital expenses will be higher than the outlays for women for the first time in our forecasts. We also 
project that total expenditure will peak at 23 billion Euros for women and 26 billion Euros later than in the previous scenarios, precisely in 2050 .

Figures $6 \mathrm{a}$ and $6 \mathrm{~b}$ about here

These absolute numbers translate into a widening gap between future expenses for men and women compared to their outlays in 2000. By 2050, hospital expenditure for older women will have risen by $60 \%$, while men's expenses will be $150 \%$ higher than in 2000.

Figure 7 about here

Disease-specific expenditure profiles show that medical progress leads to expenses that are substantially lower for women and higher for men in most of the cases and for the two major killers, ICD 7 and ICD 2, with the exception of respiratory diseases. As to the latter, outlays for women will have multiplied by four by 2065 , while hospital costs for men will have increased by $124 \%$.

It is beyond the scope of this paper to explain why men benefit from medical progress more so than women do. We can only make assumptions here and they should be taken with care since small differences at the beginning of the projection period become stark effects in the long run. Nevertheless, it is plausible to assume that agism and sexism leads to an unequal expenditure profile (Brockmann, 2002). Also, changes in the life styles, like an increase in the number of women who smoke, are likely to determine future expenditure for the treatment of diseases of the respiratory system (Caselli, 1996). There is 
ample room for future research to analyze these relationships; for now, however, we have to take them as given.

\section{DISCUSSION}

Forecasts are always wrong. But some do more so than others. Many forecasts that predict an impending crisis of health care financing are likely to be inaccurate because they are based on multiple deterministic assumptions and on aggregate data. The problem with the latter is that they tend to be confounded by different effects that operate on a level less aggregated. As to the assumptions, especially on future revenues, it is difficult to make accurate ones when the predictions are merely based on the past. Arbitrary assumptions on future fertility rates, migration rates, or economic growth bias the forecast.

Avoiding confounded data is straight forward. In this paper, we use longitudinal, individual-level hospital expenditure data over the life-course. Avoiding arbitrary assumptions is, naturally, much more tricky. For this reason, we confine our forecast to expenditure for elderly alive, whose mortality rates can be well predicted from past years. Using three probabilistic scenarios, we show the effect that a growing elderly population (Scenario One), their improving health status (Scenario Two) and technological advancement (ScenarioThree) has on hospital expenditure.

In all three cases, our forecasts predict that hospital expenditure for people aged 65 and above will increase in Germany between 2040 and 2050, but the rise will not result in cost explosion. When the German baby boomers - born between 1955 and 1969 - have died out, costs will decline. In the first scenario, this is translated into an increase in hospital expenditure of up to $220 \%$ and $160 \%$ for elderly men and women, respectively, compared 
to the expenses of 2000 . The gender gap can be explained by an age-specific expenditure profile that shows a decline at the highest ages; a decline that a larger fraction of future elderly women will reach (Brockmann, 2002).

However, life-course studies further reveal that longevity brings in its wake a better health status (see, for example, Lubitz, Beebe \& Baker, 1995; Yang, Norton \& Stearns, 2003). If we allow for a future older population that is healthier, then the increase in hospital expenditures for the two sexes would be lower by roughly 20\% (Scenario Two). This overall trend would result from declining incidence rates and changing disease patterns. As a consequence, average expenses for single diseases would drop below the level of 2000. Different diseases would show different expenditure profiles, however.

Finally, medical progress defines medical treatments of the future, but contrary to suggestions by longitudinal studies it does not necessarily lead to increases in hospital expenditures. We find an ambiguous impact of medical progress on hospital expenditure when we apply past empirical indicators of medical progress that mirror the patient's and public's priorities - more treatments and speedier recovery (Scenario Three). Medical progress will increase hospital expenses only for men and, again, its impact varies by disease.

To conclude, the overall costs of population aging are driven by various individual level factors that evolve differently over time. More precisely, gender and disease-specific differences are prominent in all scenarios. They are not time-constant but sensitive to behavioral changes and social determinants. They also provide a strong basis for effective and efficient prevention measures capable of promoting health and containing costs. Probablistic projections of future hospital costs should include empirically supported gender differences and likely distinctions between the diseases. 
Chronological age is a misleading indicator for the impact of population aging on hospital expenses, as long as it is not broken down into life-cycle needs. The latter will result in an increase in the projected absolute hospital costs. Nevertheless, there are no grounds to believe that these expenditures will outpace the increase in revenues. Assuming an annual economic growth rate of $2 \%$, which is a standard assumption for developed economies, the GDP will be 2.44 times higher in 2045 than in 2000. In our projections, overall hospital expenses will grow at a lower rate; this means that they would be covered by economic growth without the need for policy change. Increases in hospital expenditure seems to remain moderate even if we allow prices for hospital care to increase at a higher rate - it is often assumed that they may increase at a rate $1 \%$ higher than the economy grows, because services are labor intensive and productivity growth may be slower in the hospital sector.

We do not contend the desirability and necessity of public health care reform and cost containment policies. Just the contrary, our projection demonstrates the importance of appealing to the patient's preferences for prevention and effective and efficient health care. Only when the payers and user of public health care become an important factor in deciding the routes to take in medical care and medical progress will costs be less likely to explode. This is also true for medical services other than hospital care. Given these findings and projections, we call the necessity and benefit of age rationing into question. There is evidence that we can afford population aging without implementing further age discriminating policies. 
Figure 1a: Absolute Future Hospital Expenses Of A Growing Older Population

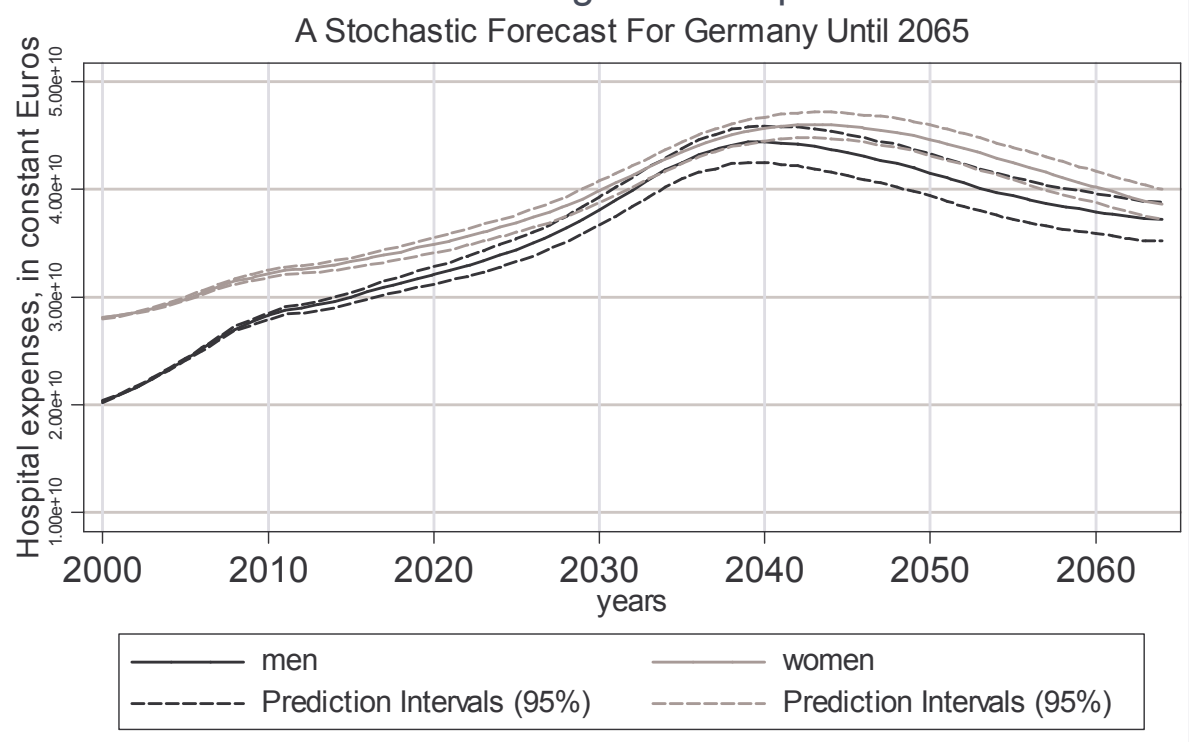

Source: HMD, AOK, ow $n$ calculations

Figure 1b: Relative Future Hospital Expenses Of A Growing Older Population

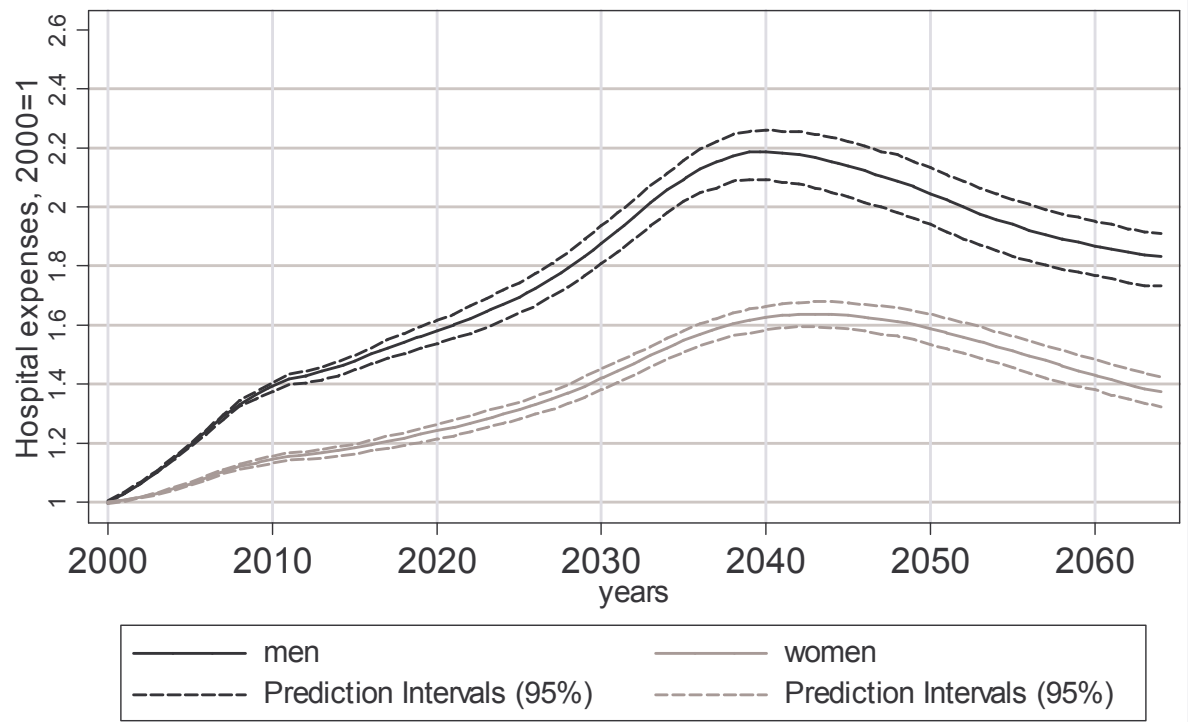

Source: HMD, AOK, ow $n$ calculations 
Figure 2: Average Future Hospital Expenses

Of A Growing Older Population In Germany

A Stochastic Forecast until 2065

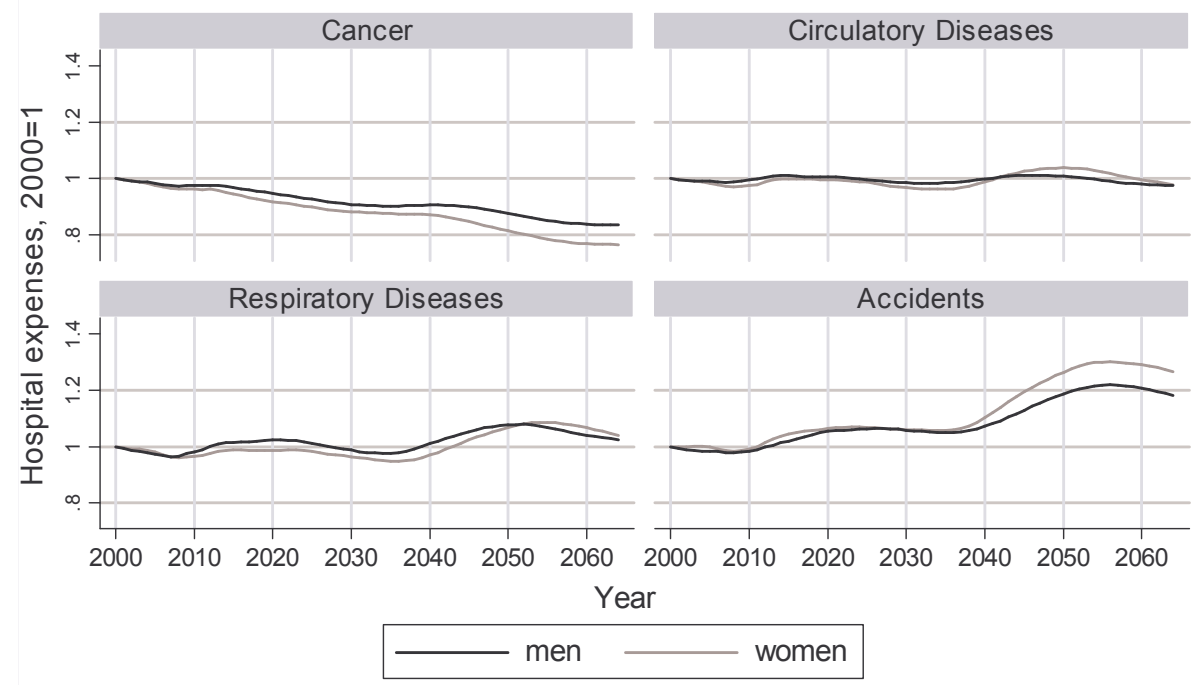

Source: HMD, AOK, ow n calculations

Figure 3a: Absolute Future Hospital Expenses Of A Growing, Healthier Older Population

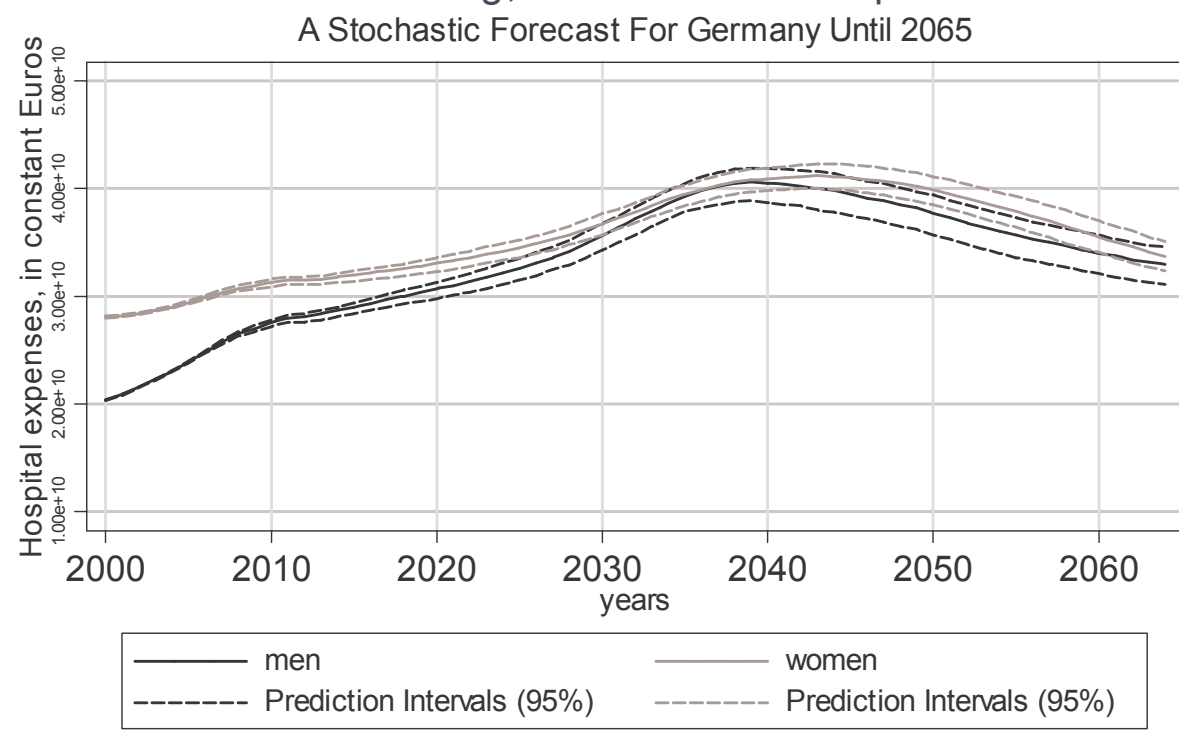

Source: HMD, AOK, ow $\mathrm{n}$ calculations 
Figure 3b: Relative Future Hospital Expenses

Of A Growing, Healthier Older Population

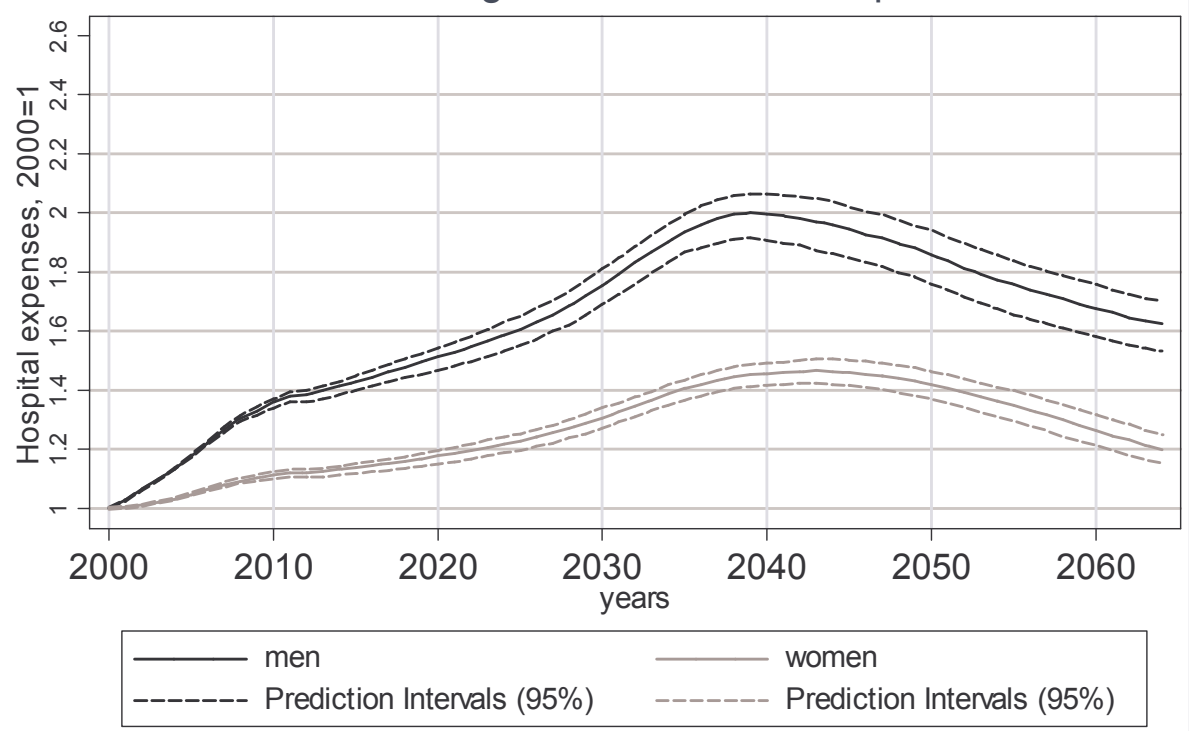

Source: HMD, AOK, ow $n$ calculations

Figure 4: Average Future Hospital Expenses

Of A Healthier Older Population In Germany

A Stochastic Forecast until 2065

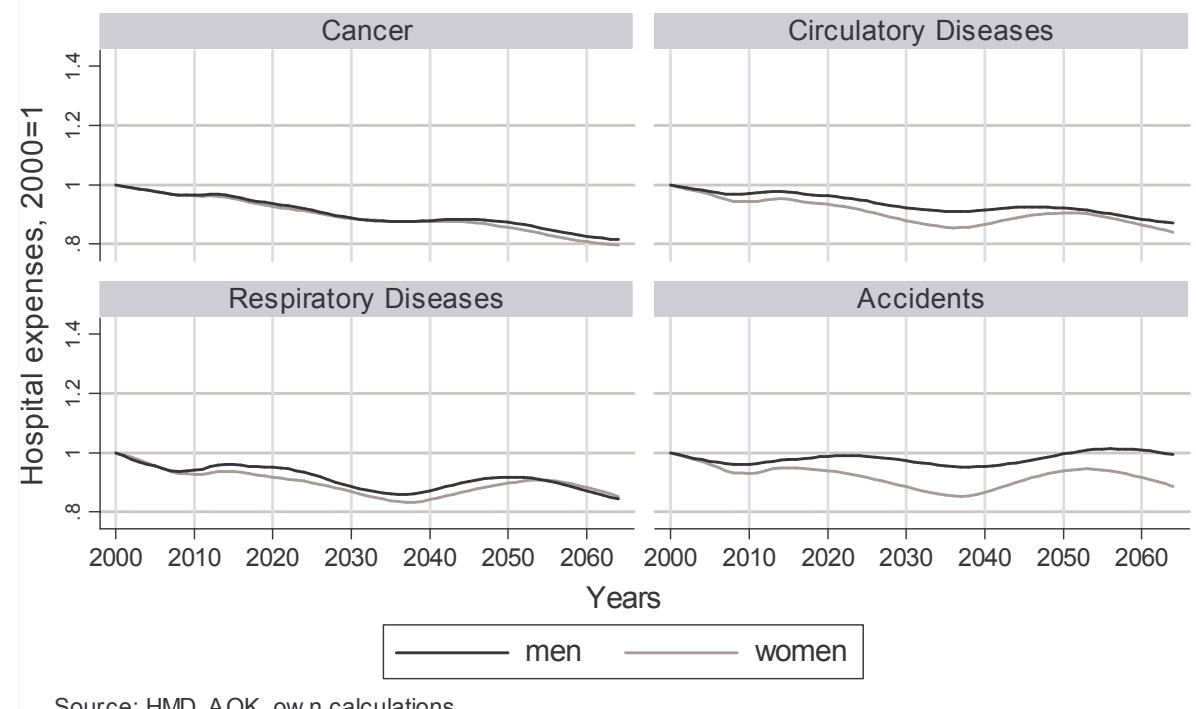


Figure 5: Future Hospital Expenses

By Reducing the Length of Stay

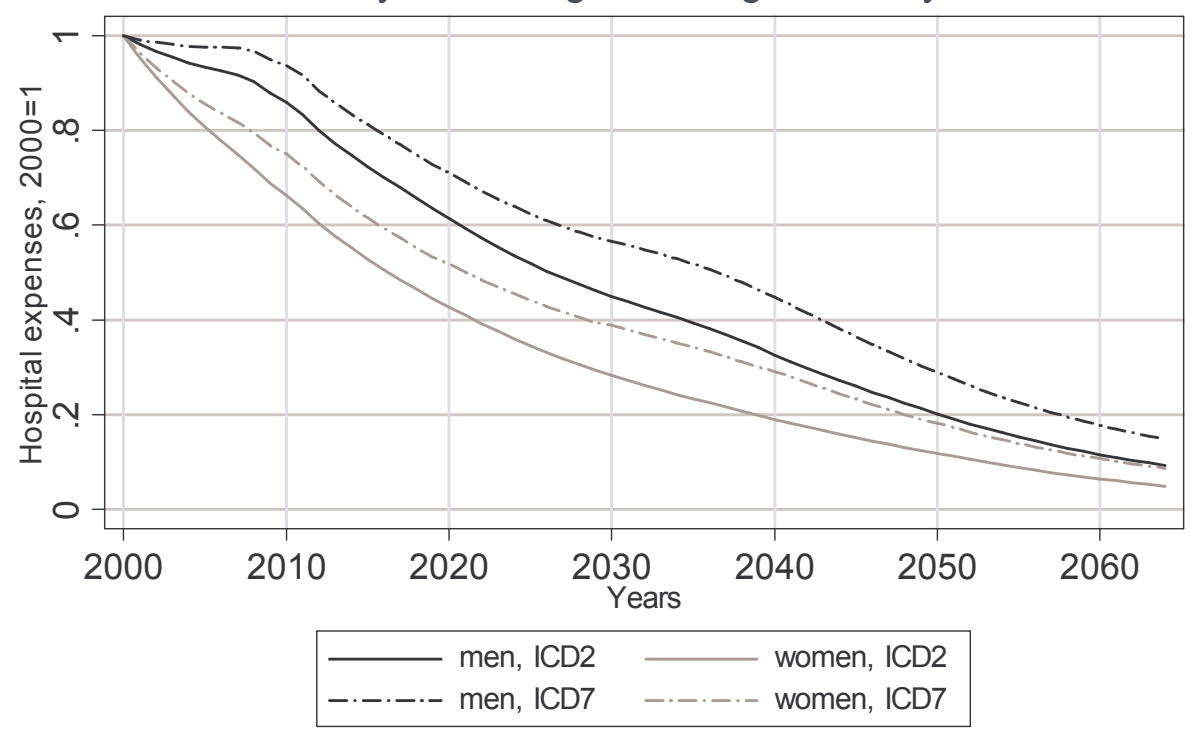

Source: HMD, AOK, ow n calculations

Figure 6a: Absolute Future Hospital Expenses

Of A Growing, Healthier, Older Population And Medical Progress

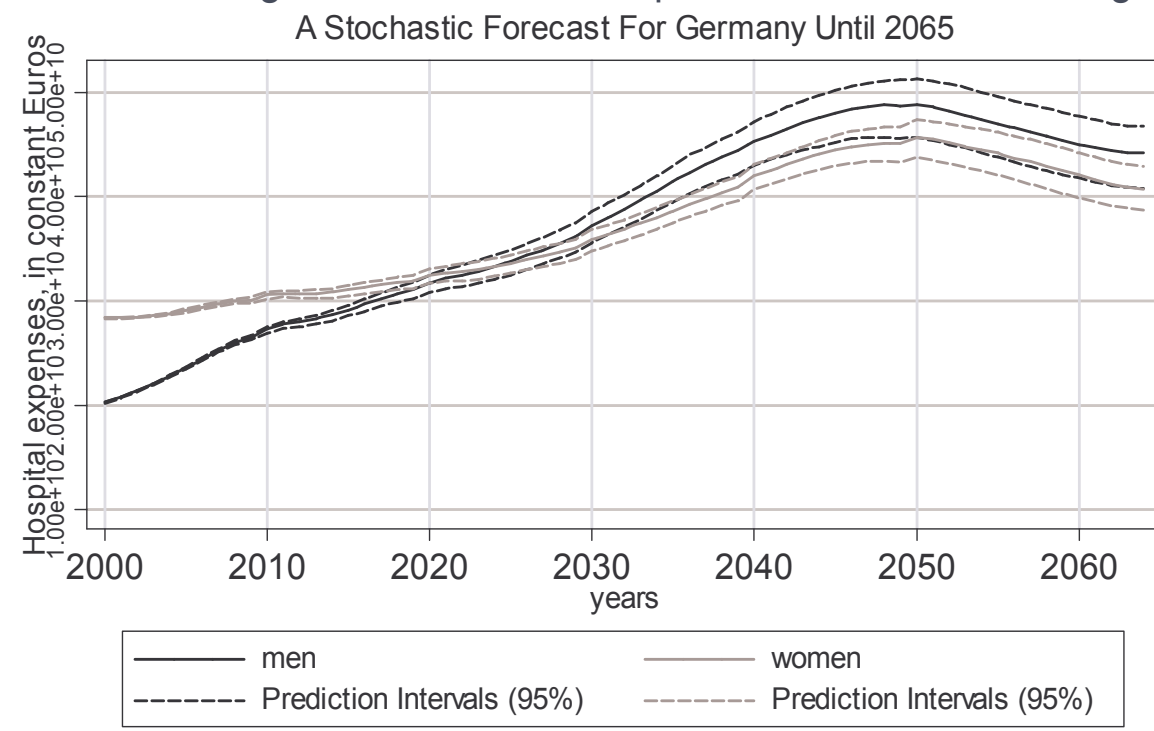

Source: HMD, AOK, ow n calculations 
Figure 6b: Relative Future Hospital Expenses

Of A Growing, Healthier, Older Population And Medical Progress

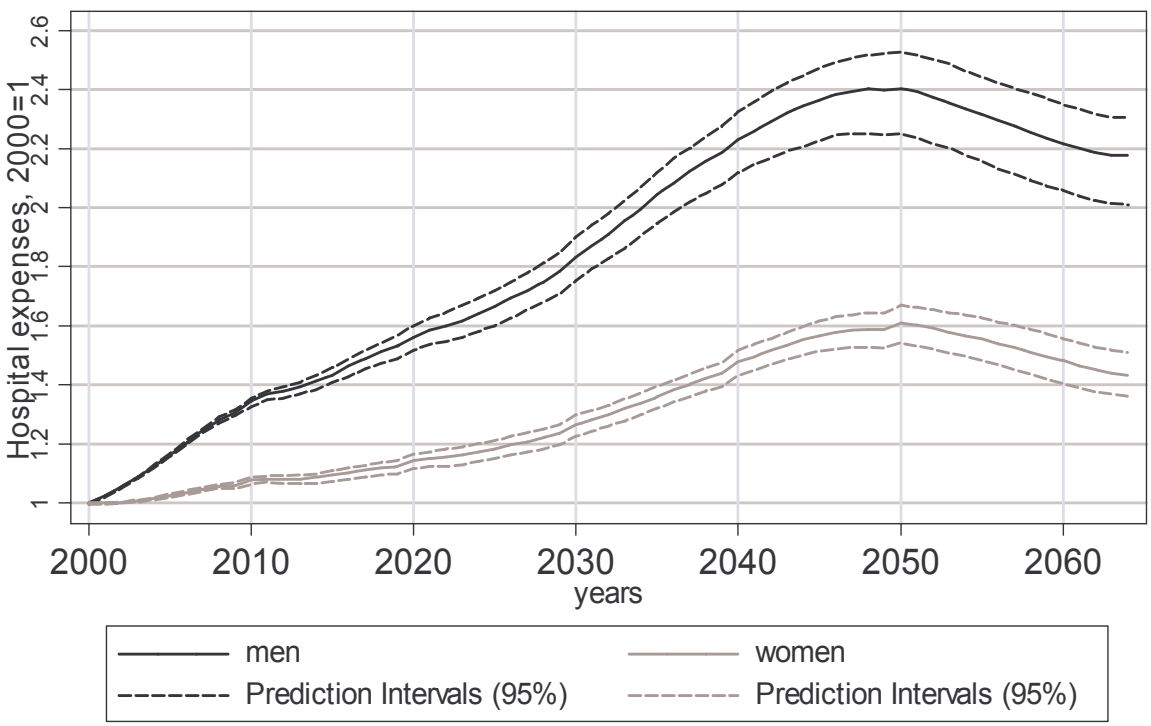

Source: HMD, AOK, ow n calculations

Figure 7: Average Future Hospital Expenses With Healthier Future Elderly and Medical Progress

A Stochastic Forecast until 2065

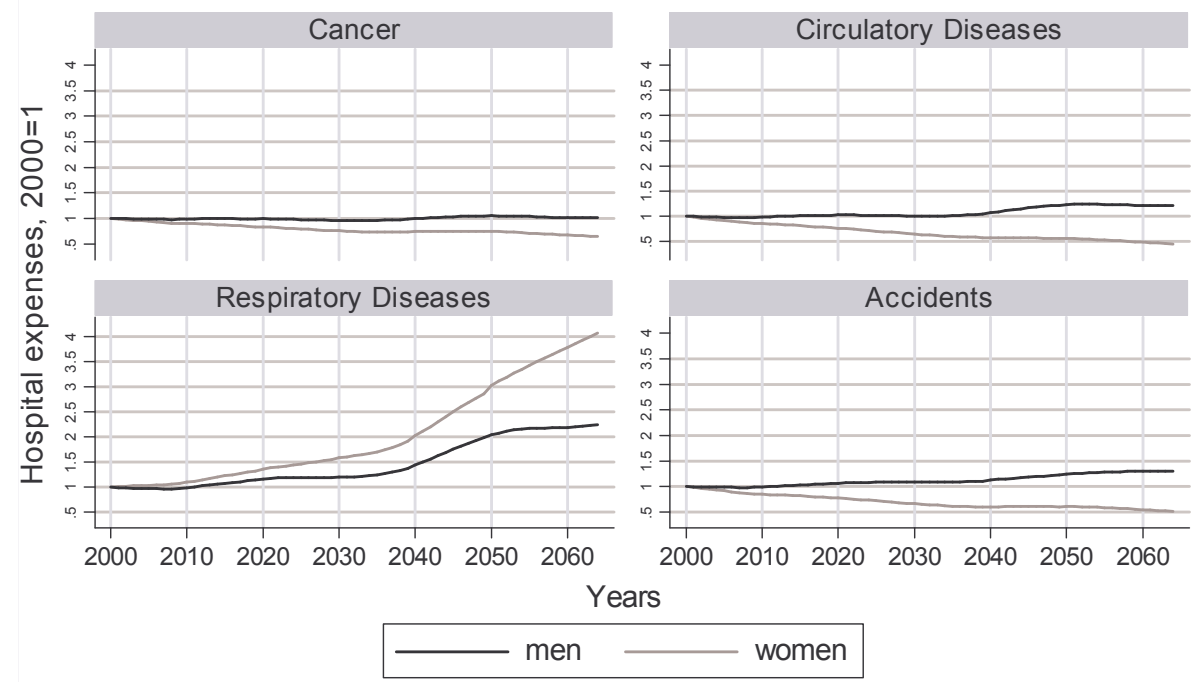

Source: HMD, AOK, ow n calculations 


\section{APPENDIX}

\section{A1. Demographic Forecasts: Lee-Carter-Model}

The predicted numbers of future elderly are obtained by applying the Lee-Carter model (henceforth LC model, Lee \& Carter, 1992) to data on West Germany from the Human Mortality Database (available online, see references).

Let $m_{x, t}$ denote the age-specific death rates for age $x$ in year $t$ $(x=1, \ldots, K, t=1, \ldots, T)$. The LC model decomposes the logarithm of these rates as

$$
\ln m_{x, t}=a_{x}+b_{x} k_{t}+e_{x, t}
$$

subject to the constraints $\sum_{x} b_{x}^{2}=1$ and $\sum_{t} k_{t}=0$. Let $e_{x, t}$ represent zero-mean and uncorrelated error terms; thus, $a_{x}$ denotes the age-specific averages of $\ln m_{x, t}$ over time, that is $a_{x}=\frac{1}{T} \sum_{t} \ln m_{x, t}$. As suggested by Lee and Carter (1992), using the singular value decomposition for estimating the $b_{x}$ - and $k_{t}$-schedules is equivalent to $b_{x}$ being the first principal component (PC) loadings, and $k_{t}$ being the first PC scores of the centered log rates $\left(\ln m_{x, t}-a_{x}\right)$. Given that the first PC picks up a large proportion of the original variability, errors $e_{x, t}$ will be small, and $b_{x} k_{t}$ will be a good approximation to $\left(\ln m_{x, t}-a_{x}\right)$

Forecasts are then based on a time-series model for the first PC $k_{t}$, given it captures a large proportion of the original variance. In many applications, it has been assumed that the first order differences can be modeled adequately as $\nabla k_{t}=k_{t}-k_{t-1}=c+x_{t}$, where $x_{t}$ denotes white noise. In this case, model (1) has an additional convenient interpretation: 
each age-specific death rate declines at its own specific rate. This is achieved by retransforming to the original scale.

Data for both parts of Germany are available in the Human Mortality Database for the years 1956 onwards. Death rates and population counts are given by single years of age and single period-years, for both sexes separately. We used data up to 1999, and ages of 95 and over were collapsed into a single age-group, $95+$, to attenuate large fluctuations due to small sample sizes.

The following figures give the first two PC scores (kt1 and kt2, top row) and the first two PC loadings (bx1 and bx2, bottom row) for West German males and females, respectively. The cumulative variance proportions captured by the two PCs are provided in Table A1.

Figure Ala: First two PC scores (top row) and PC loadings (bottom row) for West German males, period of analysis: $1956-1999$.
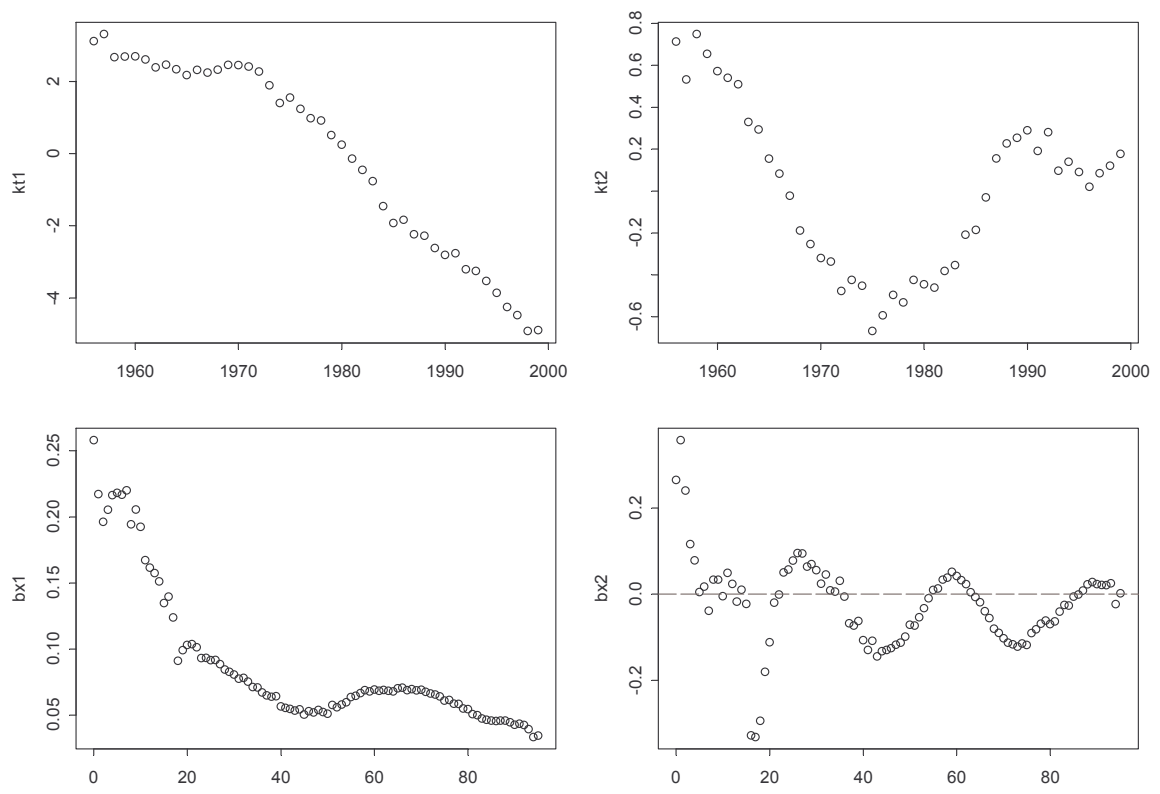
Figure A1b: First two PC scores (top row) and PC loadings (bottom row) for West German females, period of analysis: $1956-1999$.
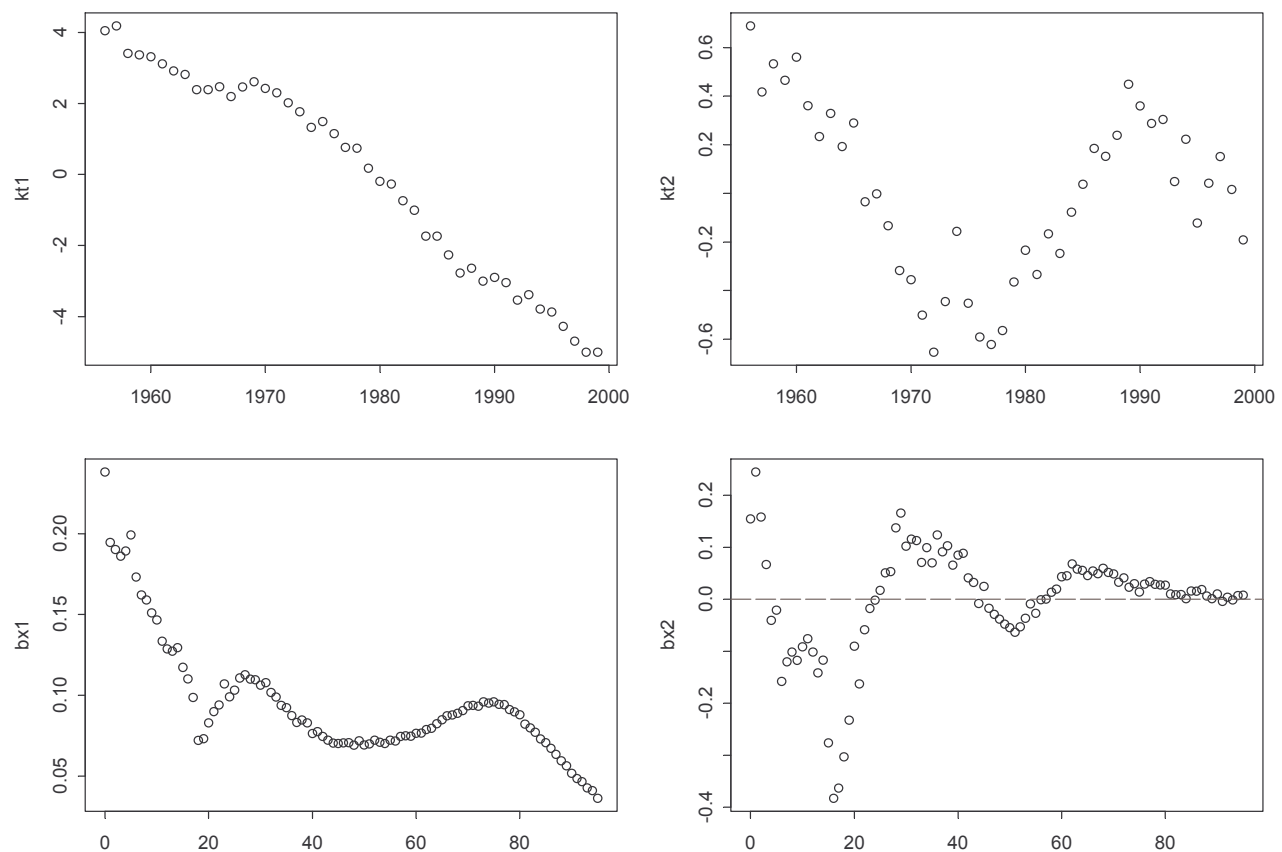

Table A1: Cumulative variance proportions for the first two PCs and two different periods of analysis; West German males and females.

\begin{tabular}{c|cc|ll}
\hline & \multicolumn{2}{|c|}{$\begin{array}{l}\text { LC model } \\
1956-1999\end{array}$} & \multicolumn{2}{l}{$\begin{array}{l}\text { LC model } \\
1970-1999\end{array}$} \\
\hline $\begin{array}{c}\text { Cumulated Variance } \\
\text { Proportion }\end{array}$ & males & females & males & females \\
\hline 1. PC & $94 \%$ & $94 \%$ & $94 \%$ & $93 \%$ \\
$1 . \& 2$. PC & $96 \%$ & $96 \%$ & $95 \%$ & $94 \%$ \\
\hline
\end{tabular}

For West German men as well as women, the resulting $b_{x}$ - and $k_{t}$-schedules for the first component resemble the schedules found for several other countries: The first PC, 
which is a weighted average of the input variables, is a highly regular series. The variance proportion of $94 \%$ is in accordance with the percentage reported for the G7 countries (Tuljapurkar, Li \& Boe, 2000).

Time component $k_{t}$ shows a linear trend for both West German males and females from about 1970 onwards. If one considered forecasting mortality from the entire 19561999 trajectory, then a simple first order difference model for common index $k_{t}$ would be inappropriate; a preliminary exploration indicates that a second order difference would offer a stationary series for further ARMA modeling. An alternative is to restrict the analysis to the time interval 1970-1999. This would lead to a more convenient model for the time component. As it seems reasonable to assume that the mechanisms driving mortality changes over the last three decades will be the most important forces for the years to come, a shorter basis for projecting mortality is favored. Reducing the period range by 14 years does not worsen the fit of the model. The loss of about $1 \%$ in the variance subsumed in the first PC (cf. Table A1, right column) can safely be neglected.

For West German females, Figure 2a provides a summary of the analysis of the resulting $k_{t}$-series. First order differences remove the linear trend, rendering a stationary series of clear AR(1)-structure, which is confirmed by a more formal analysis. ${ }^{1}$ That is, the model for the time index is

$$
\nabla k_{t}=k_{t}-k_{t-1}=c+x_{t},
$$

where

$$
x_{t}=\phi_{1} x_{t-1}+w_{t}
$$

is an $\operatorname{AR}(1)$ process, which means an $\operatorname{ARIMA}(1,1,0)$ specification for series $k_{t}$.

\footnotetext{
${ }^{1}$ In their original publication (1992), Lee \& Carter also mentioned that an AR(1) model gave a slightly better fit than the finally chosen random-walk with drift specification.
} 
The model parameters were estimated as

$$
\hat{c}=-0.26 \quad \hat{\phi}_{1}=-0.438 \quad \hat{\sigma}_{w}^{2}=0.05 .
$$

Standard prediction techniques for ARIMA processes can be used to forecast $k_{t}$.

Figure A2a: A time-series analysis of first PC scores, West German females, 1970-1999. Top row: Original series and first differences. Middle row: ACF and PACF for the differenced series. Bottom row: Residuals and their ACF for a fitted AR(1) model.
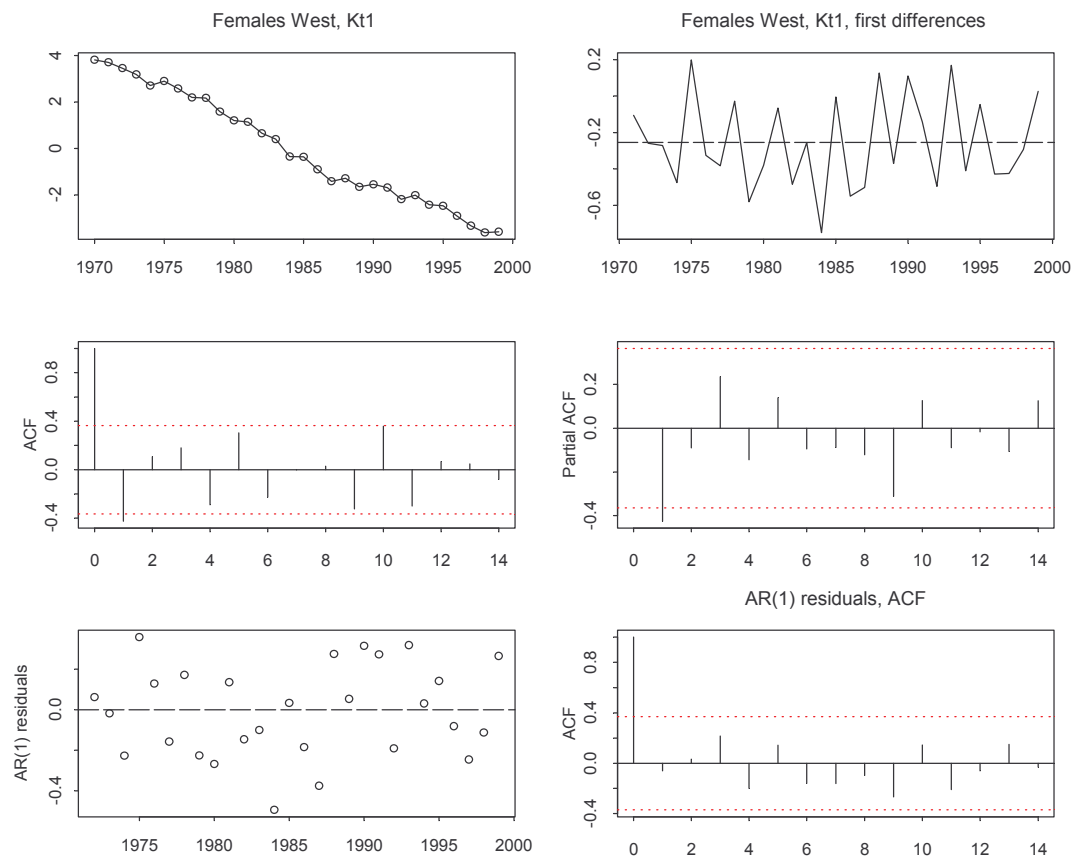

For West German males, a parallel analysis provides the results in Figure A2b. Here, the structure of first order differences resembles a white noise process, though AR-order selection via AIC again results in an AR(1) model. 
For males, the parameters were estimated as

$$
\hat{c}=-0.27 \quad \hat{\phi}_{1}=-0.27 \quad \hat{\sigma}_{w}^{2}=0.04 .
$$

Figure A2b: Time-series analysis of first PC scores, West German males, 1970-1999. Top row: Original series and first differences. Middle row: $\mathrm{ACF}$ and PACF for the differenced series. Bottom row: Residuals and their ACF for a fitted AR(1) model.
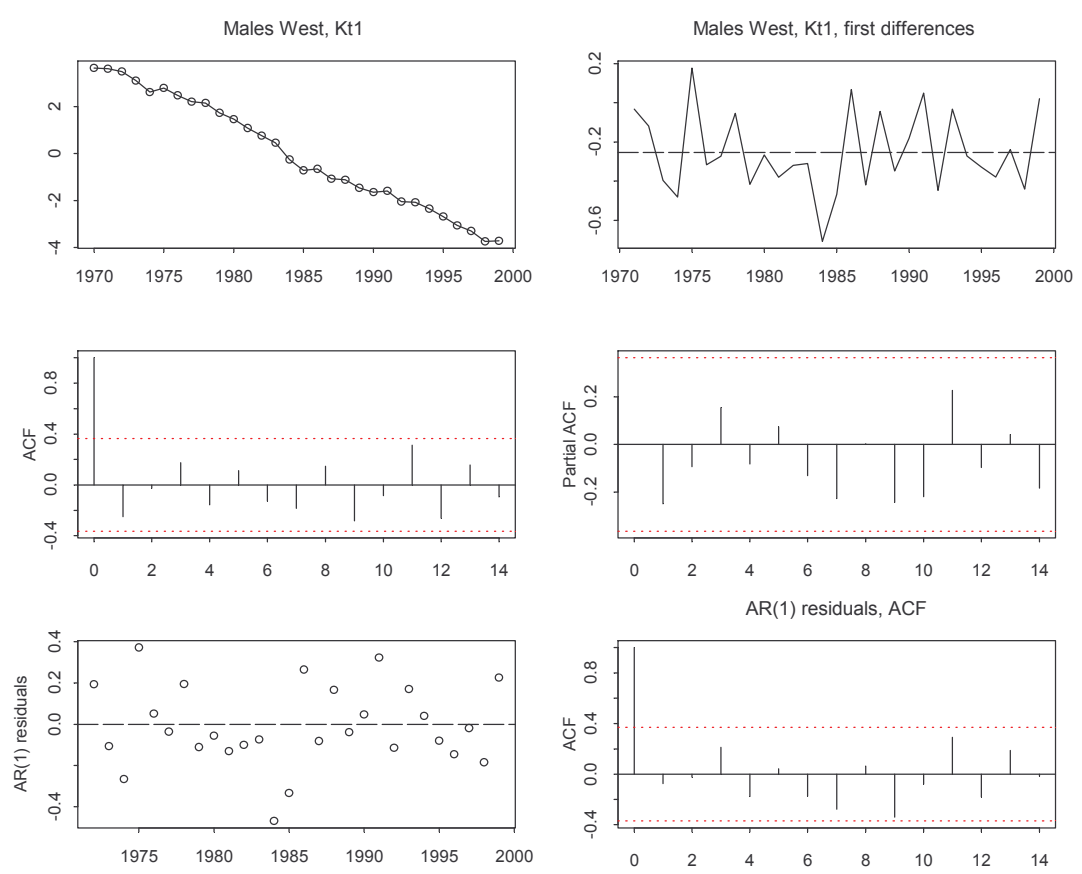

Based on the estimated time-series models and PC weights $b_{x}$, predicted future death rates can be derived. Therefrom, the number of individuals at age $x$ in year $t$ were determined from the population counts in 1999. To capture the uncertainty of these predictions, $S=200$ simulation replications were run from this model. For estimating 
hospital costs, the number of deceased persons $D_{x, t}$ and survivors $S_{x, t}$ of each sex are needed (see section A2).

\section{A2. Regression Models for Individual Costs and Individual Lengths of Stay}

For individual hospital costs $y$, the following regression model was estimated, with $x_{1}$ being the length of stay (in days) and $x_{2}$ denoting the age of the patient:

$$
\log y=\beta_{0}^{I C D}+\beta_{1} \log x_{1}+\beta_{21} x_{2}+\beta_{22} x_{2}^{2}+\varepsilon .
$$

Here, $\beta_{0}{ }^{I C D}$ denotes an ICD-specific intercept and $\varepsilon$ represents $N\left(0, \sigma_{\varepsilon}^{2}\right)$. Separate models were estimated for men and women, deceased and non-deceased patients, resulting in four sets of parameter estimates $\left(\hat{\beta}, \hat{\sigma}_{\varepsilon}^{2}\right)$, displayed in Table A2.

Table A2: Determinants of Hospital Costs, Robust Regression Estimates

\begin{tabular}{|l|l|l|l|l|}
\hline & \multicolumn{2}{|l|}{ Males } & \multicolumn{2}{l|}{ Females } \\
\hline & survived & Deceased & Survived & Deceased \\
\hline Length of stay $(\log )$ & 0.907 & 0.949 & 0.87 & 0.953 \\
\hline Age & 0.01 & -0.021 & 0.033 & -0.028 \\
\hline Age $^{2}$ & -0.001 & 0.001 & -0.001 & 0.001 \\
\hline$\sigma$ & 0.376 & 0.327 & 0.351 & 0.302 \\
\hline
\end{tabular}

To integrate into a forecast this regression, which is conditional upon age and the length of stay, both covariate values have to be given. The individual values of $x_{1}$ have to be determined appropriately. The length of stays in hospital vary by sex, ICD, between deceased and surviving patients, andby age (see Figures A3a and A3b; age-groups are 65$74,75-84,85-94$, and $95+$ ). Therefore, the individual values of $x_{1}$ were simulated from 
these distributions (by the usual approach of simulating random numbers from a standard uniform distribution and inverting the corresponding cumulative distribution functions).

Figure A3a: Cumulative distribution functions for different ICDs, age-groups and deceased versus non-deceased female patients.
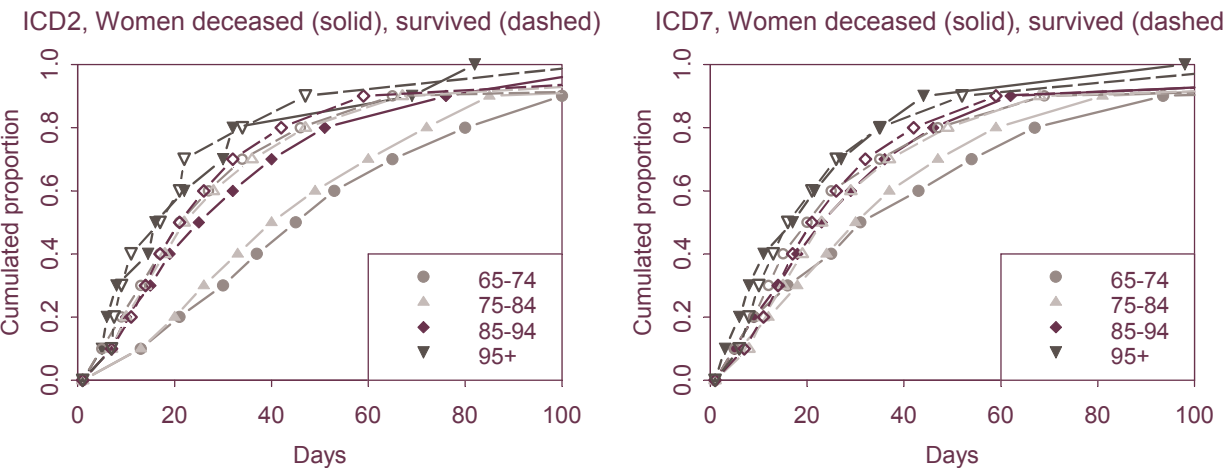

ICD8, Women deceased (solid), survived (dashed)

ICD17, Women deceased (solid), survived (dashed)
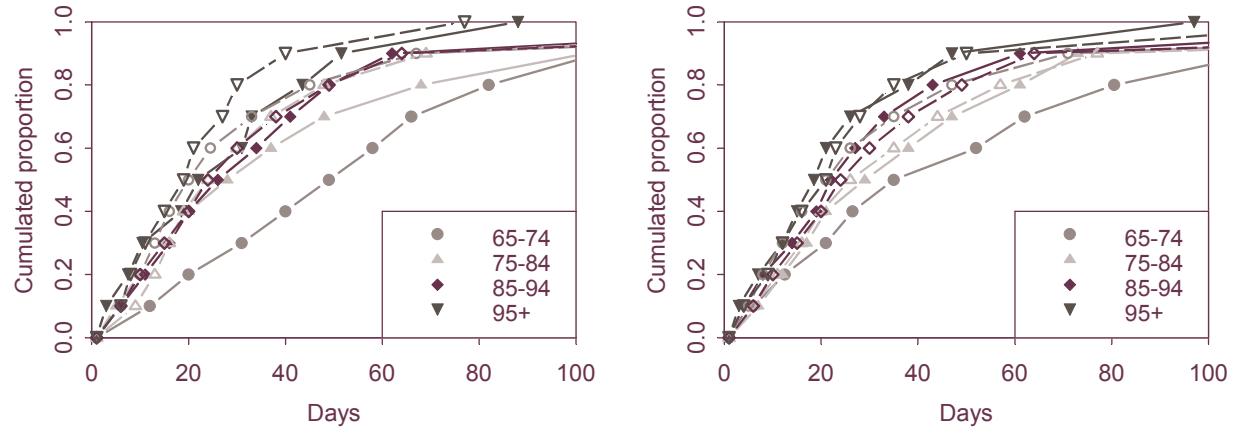
Figure A3b: Cumulative distribution functions for different ICDs, age-groups and deceased versus non-deceased male patients.
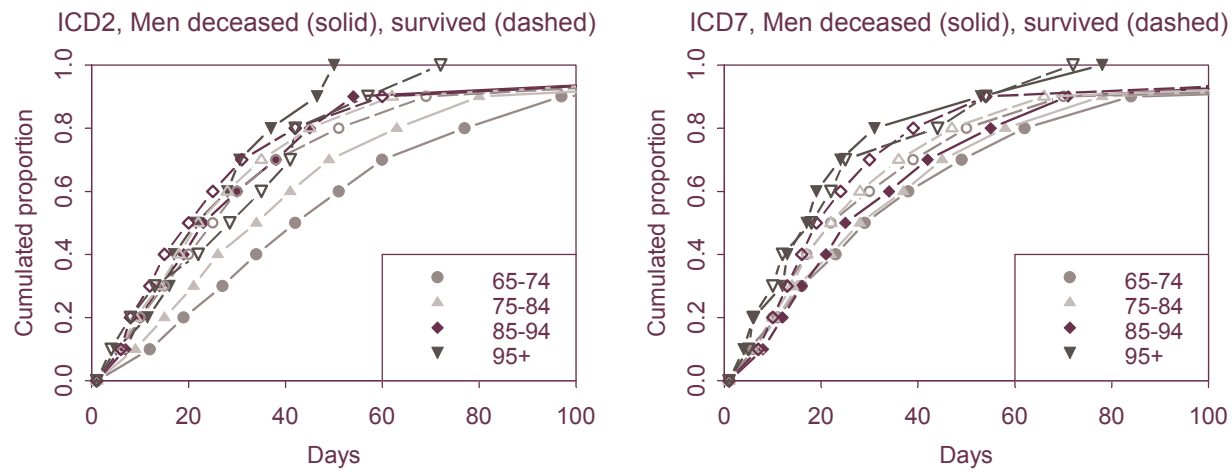

ICD8, Men deceased (solid), survived (dashed)

ICD17, Men deceased (solid), survived (dashed)
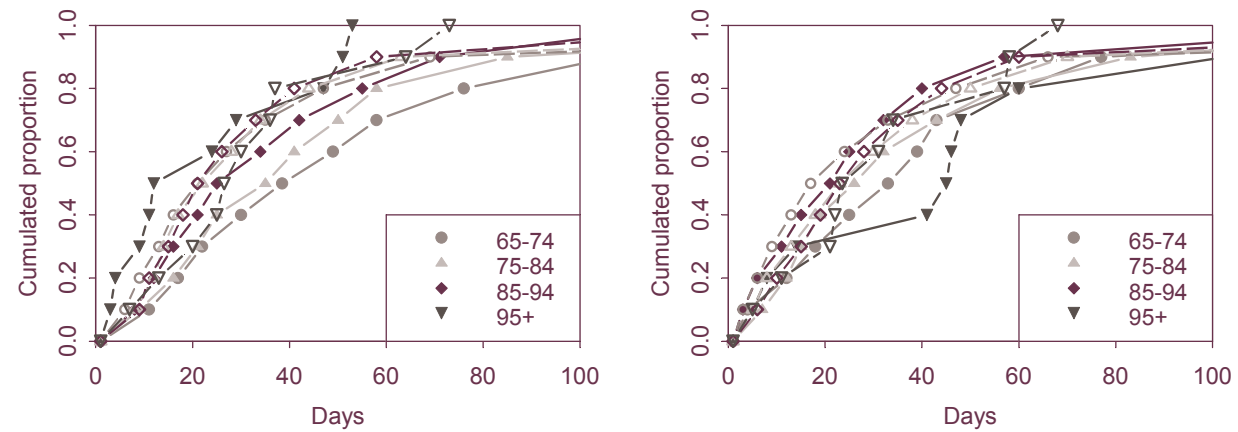

Given a patient's age and his or her length of stay, the costs are then simulated from the above regression model, matched by sex, ICD, and survival status.

\section{A3. Age-Specific Incidences}

To determine from a given number of individuals the number of patients in need of hospital care, the sex-, age-, and ICD-specific incidences of hospitalization need to be estimated. As the cost regression (see previous section) is different for deceased and surviving patients, these incidences have to be estimated separately for both groups. For this purpose, the AOK provided the number of insured persons by sex, age, and survival status as well as the resulting patient numbers, broken down by ICD. The corresponding 
proportions are shown in Figure 4. The smooth curves are loess smooths (cf. R Manual, see references) that will allow to smoothly vary these incidences in some of the simulation scenarios. If $p_{g, s}^{j}(x, t)$ denotes the proportion of individuals of sex g, survival status s, and age $\mathrm{x}$ in need of hospital care because of ICD $\mathrm{j}$ in year $\mathrm{t}$, then a multiplication by the corresponding numbers $D_{x, t}$ and $S_{x, t}$ from the Lee-Carter forecasts will give the actual number of patients whose individual costs will have to be estimated from the matched regression equation (3).

Figure A4: Age-specific incidences of hospitalization for different ICDs, separately for sex and survival status.
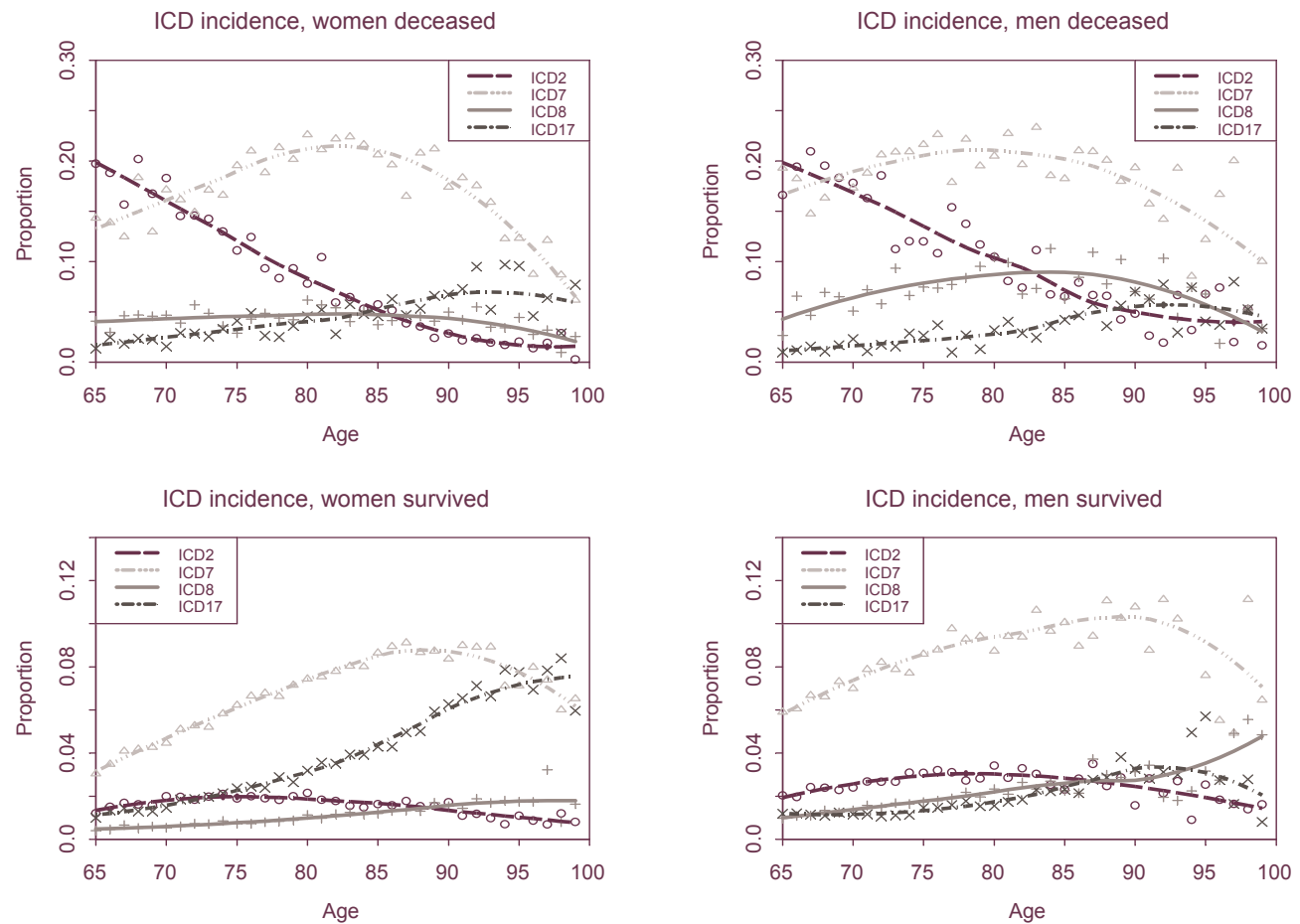

Stays

In Scenario 3, two different modifications were introduced to mimic the effects that medical progress might have. Firstly, the lengths of stay for individuals were simulated (cf. section 3) so that every ten years one additional age was shifted to a lower age-group. While for the first decade durations were drawn from the lowest age-category only for people aged 65-74, for the second prediction decade also individuals aged 75 were assigned durations from this age-group, and so forth. That is, not only were incidences "rejuvenated" but also treatment features (= length of stay). Furthermore, all patients in this scenario benefited from an annual decline in hospitalization duration. These annual rates of decrease were derived from official German health statistics for the years 19931999. The average annual reduction factors are given in Table A3, separately for sex, ICD and two age-groups $(65-74,75+)$.

Table A3: Annual reduction factors of length of hospitalization for different ICD- and age-groups.

\begin{tabular}{|lllll|}
\hline & \multicolumn{2}{c}{ Males } & \multicolumn{2}{c|}{ Females } \\
\hline Age & $65-74$ & $75+$ & $65-74$ & $75+$ \\
\hline ICD 2 & 0.9598 & 0.9611 & 0.9950 & 0.9541 \\
\hline ICD 7 & 0.9481 & 0.9544 & 0.9411 & 0.9453 \\
\hline ICD 8 & 0.9630 & 0.9663 & 0.9582 & 0.9488 \\
\hline ICD 17 & 0.9670 & 0.9624 & 0.9561 & 0.9490 \\
\hline Other & 0.9516 & 0.9556 & 0.9459 & 0.9460 \\
\hline
\end{tabular}

Secondly, the number of cases were increased by an annual factor, which was also derived from official German health statistics (Statistisches Bundesamt, 2003b). Hence, 
instead of solely simulating the number of patients from the incidences, each individual created an increasing number of hospitalization events, each of which was of reduced duration, however. Table A4 displays the factors that were used to create this annual increase.

Table A4: Annual -relative increase in hospitalization events per individual, for different ICD- and age-groups.

\begin{tabular}{|lllll|}
\hline & Males & \multicolumn{3}{l|}{ Females } \\
\hline Age & $65-74$ & $75+$ & $65-74$ & $75+$ \\
\hline ICD 2 & 1.038 & 1.042 & 1.028 & 1.041 \\
\hline ICD 7 & 1.033 & 1.045 & 1.042 & 1.041 \\
\hline ICD 8 & 1.023 & 1.053 & 1.034 & 1.074 \\
\hline ICD 17 & 1.033 & 1.039 & 1.028 & 1.036 \\
\hline Other & 1.030 & 1.048 & 1.035 & 1.056 \\
\hline
\end{tabular}




\section{REFERENCES}

Bell, W. R. (1997). Comparing and assessing time series methods for forecasting agespecific fertility and mortality rates. Journal of Official Statistics, 13(3), 279-303.

Blumenthal, D. (2001). Controlling health care expenditures. The New England Journal of Medicine, 344(10), 766-769.

Board of Trustees of the Federal Hospital Insurance Trust Fund (2002) Annual Report 2000. Washington, DC.

Booth, H., Maindonald, J., \& Smith, L. (2001). Age-time interactions in mortality projection: Applying Lee-Carter to Australia (Demography and Sociology Program No.

85). Canberra ACT: Australian National University.

Breyer, F., \& Schultheiss, C. (2003a). Altersbezogene Rationierung von Gesundheitsleistungen. In E. Wille (Ed.), Rationierung im Gesundheitswesen und ihre Alternativen (pp.169-193). Baden-Baden: Nomos.

Breyer, F., \& Schultheiss, C. (2003b). Primary rationing of health services in aging societies: A narrative analysis. International Journal of Health Care Finance and Economics, 2(4), 247-264.

Breyer, F., \& Ulrich, V. (2000a). Gesundheitsausgaben, Alter und medizinischer Fortschritt: Eine Regressionsanalyse. Jahrbücher für Nationalökonomie, 220, 1-17.

Breyer, F., \& Ulrich, V. (2000b). Demografischer Wandel, medizinischer Fortschritt und der Anstieg der Gesundheitsausgaben. DIW Wochenbericht, 24, 1-8.

Brockmann, H. (2002). Why is less money spent on health care for the elderly than for the rest of the population? Hospital care rationing in German hospitals. Social Science \& Medicine, 55, 593-608. 
Brockwell, P., \& Davis, R. (1991). Time series: Theory and methods. New York: Springer Verlag.

Caselli, G., \& Lopez, A. D. (1996). Health and mortality among elderly populations. Oxford: Clarendon Press.

Cutler, D. M. (2003). An international look at the medical care financing problem. Harvard University.

Cutler, D. M., \& Huckman, R. S. (2003). Technological development and medical productivity: the diffusion of angioplasty in New York State. Journal of Health Economics, 22, 187-217.

Cutler, D. M., \& McClellan, M. (2001). Is technological change in medicine worth it? Health Affairs, 20(5), 11-29.

Cutler, D. M., McClellan, M., Newhouse, J. P., \& Remler, D. (1998). Are medical prices declining? Evidence from heart attack treatments. The Quarterly Journal of Economics, 113(4), 991-1024.

Cutler, D. M., \& Sheiner, L. (1998). Demographics and medical care spending: Standard and non-standard effects (NBER Working Paper Series No. 6866). Cambridge: National Bureau of Economic Research.

Doblhammer, G., \& Kytir, J. (2001). Compression or expansion of morbidity? Social Science \& Medicine, 52(3), 385-391.

Espenshade, T., \& Braun, R. (1983). Economic aspects of an aging population and material well-being of older persons. In M. W. Riley, B. Hess \& K. Bond (Eds.), Aging in society (pp. 25-51). Hillsdale, NY: Erlbaum Associates.

Felder, S., Meier, M., \& Schmitt, H. (2000). Health care expenditure in the last months of life. Journal of Health Economics, 19, 679-695. 
Freund, D., \& Smeeding, T. M. (2002). The future costs of health care in ageing societies: is the glass half full or half empty? Unpublished manuscript, Syracuse.

Garber, A. M., MacCurdy, T. E., \& McClellan, M. L. (1998). Medical care at the end of life: Diseases, treatment patterns, and costs (NBER Working Paper Series No. 6748). Cambridge: National Bureau of Economic Research.

Getzen, T. E. (1992). Population aging and the growth of health expenditures. Journal of Gerontology: Social Sciences, 47(3), 98-104.

Gjonça, A., Brockmann, H., \& Maier, H. (2000). Old-age mortality in Germany prior and after reunification. Demographic Research, 3(1).

Guillemard, A.-M. (1983). Old age and the welfare state. London: Sage.

Human Mortality Database. Available online at http://www.mortality.org

Kannisto, V., Lauritsen, J., Thatcher, A. R., \& Vaupel, J. W. (1994). Reductions in mortality at advanced ages: several decades of evidence from 27 countries. Population and Development Review, 20,793-810.

Keilmann, N. (1998). How accurate are the United Nations world population projections? Population and Development Review, 24, 15-41.

Knappe, E. (1995). Auswirkungen des demographischen Wandels auf den Gesundheitssektor. In P. Oberender (Ed.), Transplantationsmedizin: Ökonomische, ethische, rechtliche und medizinische Aspekte (pp. 11-41). Baden-Baden: Nomos.

Lee, R. D., \& Carter, L. R. (1992). Modeling and forecasting U.S. mortality. Journal of the American Statistical Association, 87(419), 659-675.

Lee, R. D., \& Miller, T. (2001a). An approach to forecasting health expenditures, with application to the U.S. Medicare system. Unpublished manuscript. London. 
Lee, R. D., \& Miller, T. (2001b). Evaluating the performance of the Lee-Carter Method for forecasting mortality. Demography, 38(4), 537-549.

Lubitz, J., Beebe, J., \& Baker, C. (1995). Longevity and Medicare expenditures. The New England Journal of Medicine, 332(15), 999-1003.

Lubitz, J., \& Riley, G. F. (1993). Trends in Medicare payments in the last year of life. The New England Journal of Medicine, 328(15), 1092-1096.

Mayhew, L. (2000). Health and elderly care expenditure in an aging world (Research Report No. 21). Laxenburg, Austria: International Institute for Applied Systems Analysis.

Mayhew, L. (2001). Japan`s longevity revolution and the implications for health care finance and long-term care (Interim Report No. 10). Laxenburg: International Institute for Applied Systems Analysis.

Miller, T. (2000). Longevity and Medicare. Unpublished manuscript, Berkeley.

Miller, T. (2001). Increasing longevity and Medicare expenditures. Demography, 38(2), 215-226.

Mohr, P. E., Mueller, C., Neumann, P., Franco, S., Milet, M., Silver, L., et al. (2001). The impact of medical technology on future health care costs (Project HOPE). Bethesda.

Newhouse, J. P. (1992). Medical care costs : How much welfare loss? The Journal of Economic Perspectives, 6(3), 3-21.

Oeppen, J., \& Vaupel, J. W. (2002). Broken limits to life expectancy. Science, 296, 10291031.

Okunade, A. A., \& Murthy, V. N. R. (2002). Technology as a `major driver` of health care costs: A cointegration analysis of the Newhouse conjecture. Journal of Health Economics, 21, 148-159. 
Pardes, H., Manton, K. G., Lander, E. S., Tolley, H. D., Ullian, A. D., \& Palmer, H. (1999). Effects of medical research on health care and the economy. Science, 283(5398), 36-37.

Prognos (1998). Gutachten 1998 für den Verband Deutscher RentenversicherungsträgerAuswirkungen veränderter ökonomischer und rechtlicher Rahmenbedingungen auf die gesetzliche Rentenversicherung in Deutschland. Sonderausgabe der DRV-Schriften 9. Frankfurt/Main.

R Manual is available online at http://www.r-project.org

Report Mainz (2003). Presseinformation, Montag, 02.06.2003. Mainz: Südwestfunk.

Robine, J.-M., Mormiche, P., \& Sermet, C. (1998). Examination of the causes in mechanisms of the increase in disability-free life expectancy. Journal of Aging and Health, 10(2), 171-191.

Schroeder, S. A., Showstack, J. A., \& Schwartz, J. (1981). Survival of adult high-costs patients. JAMA, 245(14), 1446-1449.

Scitovsky, A. A. (1988). Medical care in the last twelve months of life: The relation between age, functional status, and medical care expenditures. The Milbank Quarterly, 66(4), 640-660.

Statistisches Bundesamt (Ed.). (2003a). Grunddaten der Krankenhäuser und Vorsorgeoder Rehabilitationseinrichtungen 2001 (Vol. 6.1). Wiesbaden.

Statistisches Bundesamt (Ed.). (2003b). Diagnosedaten der Krankenhauspatienten (Vol. 6.2). Wiesbaden.

Technical Review Panel on the Medicare Trustees Reports (2000). Review of assumptions and methods of the Medicare Trustees' financial projections. Report. Baltimore, MD. Thomas, L. (1980). The technology of medicine. Cambridge: Cambridge University Press. 
Tuljapurkar, S., Li, N., \& Boe, C. (2000). A universal pattern of mortality decline in the G7 countries. Nature, 405, 789-792.

Turnbull, A. D., Carlon, G., Baron, R., Sichel, W., Young, C., \& Howland, W. (1979).

The inverse relationship between cost and survival in the critically ill cancer patient. Critical Care Medicine, 7(1), 20-23.

Vaupel, J. W., Carey, J. R., Christensen, K., Johnson, T. E., Yashin, A. I., Holm, N. V., et al. (1998). Biodemographic trajectories of longevity. Science, 280, 855-860.

Waldo, D. R., Sonnefeld, S. T., Lemieux, J. A., \& McKusick, D. R. (1991). Health spending through 2030: Three scenarios. Health Affairs, 16, 231-242.

Warshawsky, M. J. (1994). Projections of health care expenditures as a share of the GDP: Actuarial and macroeconomic approaches. Health Services Research, 294-313.

Weisbrod, B. A. (1991). The health care quadrilemma: An essay on technological change, insurance, quality of care, and cost containment. Journal of Economic Literature, 29, 523-552.

Yang, Z., Norton, E. C., \& Stearns, S. (2003). Longevity and health care expenditures: The real reasons older people spend more. Journal of Gerontology: Social Sciences, $58 B(1), 2-10$.

Zweifel, P., Felder, S., \& Meier, M. (1999). Ageing of population and health care expenditure: A red herring? Health Economics, 8, 485-496.

Zweifel, P., \& Manning, W. G. (2000). Moral hazard and consumer incentives in health care. In A. J. Culyer \& J. P. Newhouse (Eds.), Handbook of Health Care Economics. (Vol.1, pp. 409-459). Boston: North Holland. 